REVISTA DE LA UNIVERSIDAD DEL AZUAY

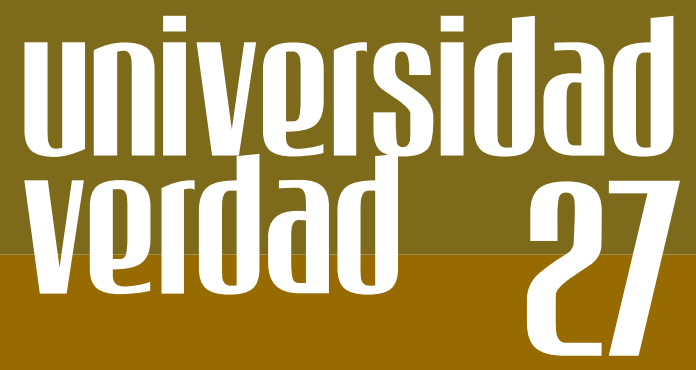

UNIVERSIDAD

DEL AZUAY

\title{
LA CHURONA LOJANA
}

Napoleón Almeida Durán

Doctor en Etnología por la Universidad Sorbona de París 


\section{SANTOS Y GUACAS}

A pesar de que los intentos por sepultar a Dios, o demostrar su inmanencia en las sociedades humanas han constituido temas fundamentales del pensamiento, y de que es el más viejo "sujeto" de la filosofía, el estudio de la religión sigue cobrando vigencia.

La antropología reconoce que es la pregunta que se hace el hombre con miedo, sobre cuestiones a las que simplemente no puede ni responder ni controlar, el basamento de la idea de ligarse a un ser superior.

La cultura latinoamericana está enraizada en creencias y sistemas sociales que ven algo singularmente el mundo. La Europa del siglo $\mathrm{XVI}$, el de la poderosa España, conquistó un mundo ya sospechado. $Y$ sospechado porque los viajeros reportaron mucho antes de que hubiese el "contacto" con el Nuevo Mundo, costumbres de pueblos lejanos, que incluían ritos de adoración a las piedras o a Creadores del Universo, en esencia el mismo Yavé cristiano. El mundo Occidental absorbía con la conquista una variabilidad cultural asombrosa existente en el Nuevo Mundo: más de tres mil lenguas habladas por cazadores de cabezas, caciques y aún reyes. En las zonas adyacentes al mundo y sus cuatro partes, Tahuantinsuyo, no existía, al parecer, la idea monoteísta del dios Sol. Fetiches e idolillos concomitantes al animismo se producen para conjurar los peligros de las almas amenazantes. Todo es religioso. La iconografía de miles de años está ligada a una visión panteísta del cosmos. No se decora una olla; se la vivifica con ricos motivos ornamentales. La vida lucha con la muerte y el signo vital es propia imagen del alfarero. Toda la producción antropomórfica en el Ecuador antiguo responde a la necesidad insondable de unirse al dios dando vida al recipiente. Y las serpientes, peces, pájaros o búhos, evocan un acendrado totemismo. 
Sin embargo, el clero regular, tal como nos lo pinta la etnohistoria, organizado para racionalizar la conquista inca, responde a una idea religiosa diferente. La religión como indicador de la convivencia y como fuente -no escrita en este caso- de prescripciones sociales. El incario había elevado la idea del Ser Supremo hasta el nivel de su irrepresentabilidad, ascendiendo él mismo a la categoría de pueblo que comparte una religión superior. Pachacámac, el padre del orbe, es un Hacedor no aludido en el arte. No hay ninguna revelación conocida pero es inmutable y eterno.

El español acarreó a América sus instituciones y su cultura. Los Visigodos habían dejado una herencia notable para que su pueblo sea el poder omnívodo de la historia durante el siglo XVI después de Cristo. La Cruz, emblema de la conquista, no significó sólo el evidente oprobio para el vencido. Lejos de eso, la imposición de un sistema de valores diferente, entraña la aniquilación de rasgos de los sometidos. En este sentido, la justificación del encomendero, que ve legitimada su conquista por la cristianización de los paganos indios, es determinante.

Cazadores de idolatrías, destructores de huacas, son puestos importantes en la administración española. La acción consecuente atentó no sólo contra la base material de la información sino imposibilitó la acumulación de datos para el sustento teológico.

Si los indios tenían en el Inti-Raymi de junio un corto lapso para adelantar cálculos astronómicos durante el solsticio de verano, y celebrar al dueño del imperio, el gran Sol, para que regale más granos, con las celebraciones de Corpus se libaba igual y se danzaba como antes.

La barroca visión del arte español de aquella época sentó sus reales sin problema.El politeísmo se seguía practicando en los costados de los altares cristianos, en donde abundaban los santos, antiguos fetiches.

Se mezcló todo. Las ideas que envolvían el quehacer político 
eran de aquí y de allá. Así por ejemplo, la famosa mita, merced a la cual el vencido debía rotar con su fuerza de trabajo, periódicamente, era ya una institución imaginada por los incas para asegurar la centralización del Estado. Por esa razón resultaba más duro el exterminar las "idolatrías", las ideas transformadas en un modo de comportamiento social.

Más rentable resultó incrementar el mestizaje pues el alma indígena es barroca, politeísta, fetichista, y la tradición española muy rica y variada. El calendario litúrgico debe satisfacer las expectativas de las diferentes órdenes religiosas, balancear las ceremonias que genera Dios, la Virgen o los Santos, equitativamente, dar paso a los milagros.

El catolicismo del español es a todas luces no sólo el pretexto para la conquista. Constituye un acto de fe sincero. Tan importante como la Trinidad es la madre del Hijo, sus apóstoles, los santos. Esto se puede verificar muy fácilmente cuando revisamos a los cronistas ibéricos oficiales y oficiosos, curas y soldados; el "príncipe" de ellos, Cieza de León es un claro ejemplo (1947), pues sobre todo la Virgen María es invocada para asegurar el éxito de la empresa.

No solamente el castellano sino todo europeo está sumergido en el Renacimiento, crucial momento de la historia occidental, quizá la única que rindió real tributo a la inteligencia humana. El hombre es el núcleo del pensamiento y su teocentrismo medieval, que había hecho gala del menosprecio a la naturaleza material, desemboca en estos nuevos tiempos en una vigorosa tentación a ensalzar no únicamente lo que abre el abismo que se dibuja entre él y la bestia, su cerebro, sino además lo que hay de común entre ellos, sus instintos. Para mucha gente de hoy, la Filosofía es mera especulación nacida de la capacidad que tiene el amo de la creación para ser ocioso; nosotros nos inscribimos en cambio en el grupo que considera que el pensador es el primer impulso de cualquier acción. Por este lado, en concordancia con la modernidad, si un Miguel Angel sobredimensiona la corpulencia de Adán, el cura se "alegra" de tener una compañera en la alcoba. 
A pesar de que durante este mismo lapso se dividió la Iglesia, merced a los inusitados planteamientos de Lutero, Calvino o Zuinglio, y de que el más radical de los reformadores, Miguel de Servet, es español, el protestantismo no se extendió a la península lbérica, sino más bien la Contrarreforma, la afirmación del catolicismo romano, tuvo exitoso eco en la actual América Latina, debido a que quienes se deshicieron con éxito de los invasores árabes, justamente los españoles, fueron los depositarios de una fe ortodoxa que determinó en buena medida el destino cultural de la mestiza aquélla. Contrarreforma es sinónimo de la Compañía de Jesús y de defensa de la tradición.

Hay que añadir a estas civilizaciones que la aceptación del protestantismo por amplios sectores de la población y de haber calado muy hondo en las capas diferentes de la sociedad europea, no trastornó en nada la vigencia de ciertas cuestiones que nos atañen.

Los milagros adjudicados a Cristo y sus apóstoles no son puestos en tela de juicio puesto que parece que todas las edades han pretendido, sin excepción de religión, ser testigas de hechos maravillosos suscitados por la deidad principal o por sus "puentes". Francisco de Asís, aparte de haber anunciado con su vida y su discurso un cambio en la historia, había testimoniado milagros. En la Francia de los Enriques III y IV, en pleno Renacimiento, la frecuencia de visionarios y estigmatizados determinó la instauración de simuladores de milagros. En efecto Nicole Tavernier fue descubierta en flagrante mentira sobre sus pretendidas premoniciones. A finales del XVIII, en Alemania, Catherine Emmerich, la "recitadora de los evangelios", veía, con la aceptación de la Iglesia, la pasión de Cristo (Hellé, 1949: 65; 263).

Resaltamos estos datos porque incluso los simuladores han determinado peregrinaciones importantes que nos permiten apreciar cómo el fenómeno religioso, en un comienzo asunto de discusión teológico, puede explicar el funcionamiento de la cultura porque a él se articulan los otros rasgos. La tal Nicole Tavernier uniformizó, tanto 
como lo hace la selección de fútbol ecuatoriana en la hora actual con la clasificación mundial de Japón y Corea de este año, las expectativas de todas las capas de la sociedad. De origen oscuro y seguramente humilde, luego de sus "milagros", los diferentes grupos la transportaban en andas reales y su efigie estampada en papel era vendida en el París de entonces como "pan caliente". Su presencia, antes de ser descubierta como mentirosa desencadenaba un fervor extraordinario y un trastorno general, un sacudón de la vida cotidiana. Es que la religión es importante para el ser humano, quien ha sido apabullado de sobrenombres como "Homo sapiens", "loquens", "erectus", o "faber", pero que es ante todo y sobre todo, "religiosus".

La Santísima Virgen empezará a reinar en el alma de millones de indios de América y muy tempranamente se aparecerá en México o Ecuador, no importa dónde. El asunto teológico no es nuestro. Sí, en cambio el resaltar la importancia de la enorme fe del pueblo en la "Ojona" lojana, la bienaventurada, la "Churona", la Negrillita Divina", la "Guagua Reina del Cielo", la "Patronita" de los militares, la Divina Virgen de El Cisne.

Los finales del siglo XVI en el Ecuador, no han mirado ni la agonía, peor la muerte de la cultura vernacular; la simbiosis cultural se da en grupos humanos entre los que "la adoración general era al sol y a la luna, y éstos hacían sus sacrificios así de ovejas como unos que llaman cuys, que parecen conejos, que crían en sus casas; y lo mismo quemando maíz y mantenimientos que ellos tienen. También tenían guacas o oratorios a quien ofrecían oro y plata y de todo lo que tenían, especialmente una hierba que se dice coca, de mucha estima entre ellos; lo cual ya no lo hacen sino a escondidas, porque se les ha advertido de la ofensa que hacen a Dios en adorar las criaturas por miedo del castigo con que se les ha prevenido..." (Salinas Loyola, 1992: 123).

Los finales del XVI, época de la aparición de la Virgen María en la localidad de EI Cisne, comenzaron a concretar las ideas expuestas. Hoy por hoy, la Advocación a la "Churona" concita igualmente el ardoroso culto del pueblo y sus procesiones forman parte de la rica 
cultura popular ecuatoriana.

Mucho se habla y escribe sobre la vigencia de algunos rasgos de las culturas indias en la sociedad contemporánea. A veces se insiste en la utilización de algunas palabras quichuas cuando utilizamos el idioma con el que oficialmente nos comunicamos, el español; creemos que este sustrato se puede vislumbrar en muchos otros aspectos pues, "La religiosidad popular tiende a penetrar en muchísimas áreas de la vida cotidiana y extracotidiana. En los sectores rurales, además de los seres sobrenaturales oficialmente aceptados y a los que se rinde culto, se coexiste con una amplia gama y variedad de espíritus que, en términos ortodoxos deberían ser prohibidos y condenados, pero que en la práctica son tolerados actuando los fieles de acuerdo con sus buenas o malas influencias, ante la vista gorda de los sacerdotes. Las imágenes de advocaciones y santos asumen en muchos casos los papeles de esos espíritus o se sincretizan con ellos. La relación del fiel con la imagen es frecuente muy familiar dándose un tipo de trato que supera las distancias entre lo profano y lo sagrado. A veces se atribuye a esas imágenes veleidades propias de la condición humana pensando el devoto que, en la práctica, está en condiciones de manipularla" (Malo González, 1996: 80-81).

Quizá no esté por demás insistir en este artículo el consignar que el hombre, en diferentes aspectos, es un ser religioso. Evidentemente, por razones inherentes a la evolución de la propia antropología, el difusionismo cultural, dominio humanista de toda una cincuentena de años, cedió paso a otras corrientes que explicaban más lógicamente el proceso de evolución social de los grupos humanos; sin embargo, a pesar de que los términos función o estructura demolieron la idea de la sobreposición de rasgos de pueblos más desarrollados en otros que no lo eran, hay que admitir que el intercambio de elementos, sobre todo los espirituales, han tenido un muy fuerte asidero en la aceptación de aquellos académicos.

En fin, "a un nivel general, las relaciones entre los sistemas religiosos pueden ser de dos suertes, hostilidad o penetración mutua. Por ahí, cosa curiosa, las articulaciones de hostilidad ellos mismos 
desembocan en préstamos o en infiltraciones. Es así que el Cristianismo, para luchar contra el paganismo ha estado obligado a prestar, modificándolos, bien entendido, y por tanto, una rivalidad es acabada en imitación.

Las asociaciones de hostilidad comprenden, yendo de menos a más, la propaganda, como aquélla de los misioneros..., las guerras de religiones, que pueden desembocar en la destrucción completa de un sistema o, en todo caso, a su limitación...

Las religiones pueden también superponerse...

Las divinidades, los ritos, pueden incluso fundirse en conjunto para arribar, en caso extremo, en una asimilación completa...

Hay, en otro sentido, en todos los casos, extremadamente numerosos, mezcla parciales, que terminan por formar sistemas religiosos enteramente nuevos, por unión a elementos heterogéneos, accionando y reaccionando los unos sobre los otros...".

Entre los principales factores de estas mezclas e infiltraciones, el autor destaca la movilidad de los grupos humanos, que llevan consigo los objetos cúlticos y la ideología propia de ellos e incluso sus santuarios. Estos conflictos e hibridaciones han dado variadísimas consecuencias; la suplantación de un dios por otro, no entraña la eliminación de la idea religiosa; así:

"...el culto de santos cristianos o mahometanos reemplaza y continúa al culto de los héroes y de los genios; el antiguo dios se mantiene, pero bajo una forma modificada...

...La metamorfosis de un sistema religioso es un sistema mágico: La magia medieval comprende todas las sobrevivencias de los viejos cultos paganos, la magia malhadada retoma, a través del islamismo, el animismo antiguo..."

La adopción de una religión adherida a una definida estructura 
social tiene un efecto de suma importancia pues se trastoca en un culto misterioso al menos en un principio... Lo que lleva a MM. Hubert y Mauss a proponer la ley siguiente: "la mezcla de las religiones se opera sobre todo por los cultos especiales"; Asia no penetró la religión latina sino por los misterios; el cristianismo se introdujo en los cultos indios por intermedio de las cofrerías...

Estos contactos conducen casi siempre a una desintegración de los antiguos sistemas aunque por lo general los sistemas vernaculares sobreviven incluso asediados por todos lados por las iglesias conquistadoras" (Bastide, 1935: 141-143; traducciones libres del francés de N. Almeida).

Por lo menos los orígenes míticos de la romería, entrañan algunos elementos bien descritos sociológicamente por Bastide.

La gran manifestación de fe de esta Advocación y de todas las pequeñas procesiones locales ciertamente debieron ser superpuestas a los ritos locales.

Seguramente esta "imposición" doctrinal fue conocida en la región lojana antes de la venida de los españoles pues ya los incas iniciaron cambios no sólo a un nivel social sino iniciaron una larga historia de control ideológico a los grupos sometidos debido a que sus festividades solares, siempre vinculadas al uso del suelo ligado a la productividad agrícola, hacían coincidir con los momentos críticos del ciclo: siembras y cosechas.

Las procesiones a la Virgen lojana, tanto durante el pasado como ahora, se realizan en períodos de gran sequía (su aparición), empatando con las faenas de "recogida" y fertilización de los suelos entre agosto y noviembre, tiempos en los que la mayor parte de productos, especialmente el maíz, son cosechados y sembrados.

Pero la fusión se da a través de ritos que remontan tal vez los tiempos del impacto inca; en efecto, el animismo que sustentaba la religiosidad palta es manifiesta pues la imagen es viva, es "llorona", 
sonríe a la gente; está viva la imagen, se mueve, tiene alma; sus estampitas que se bendicen en la iglesia de El Cisne o en Loja, son amuletos mágicos, sirven para tenerla siempre como a la "Guagua" del altar; nunca hemos visto juegos y chistes como ocurre con el Niño Viajero cuencano (González, 1981), pero de cierta manera sí le reclaman dulcemente por los tormentos que representa la travesía, pues la fatiga que acarrea la subida desde La Toma hasta las faldas del Villonaco, la entrada a la parte alta de la sierra, es realmente visible, pero es una irritación de amor, las iras que causa una buena madre exigente.

La adoración a la imagen sobrepasa en mucho los límites provinciales. En el año de 1998, en el que finalizó la investigación confiada a mí por el CIDAP desde 1993, sobre la cultura popular lojana, y parte de la cual constituyó un estudio sobre la Virgen de El Cisne, la televisión mostró a una multitud de fieles que no había podido ir a las peregrinaciones lojanas, desfilando con una réplica suya en las calles de Guayaquil en donde tiene también su fanaticada.

Ahora bien, la devoción a esta Virgen, tal vez la que más y más aglutinaba fieles en su alrededor, es uno de los más antiguos sincretismos religiosos del Ecuador.

Se trata de un fenómeno muy conocido en el mundo, como dijimos; la peregrinación basada en la aparición de la madre de Dios no es un hecho único. En la misma provincia de Loja, hace algunos años, hubo un niño con prodigios para la curación gracias a la visión, aunque el caso reciente más conocido y difundido fue la aparición de la Virgen cuya "estigmatizada" es una joven azuaya, quien desde hace más de una década asegura desfiles de fieles que acuden al "Jardín del Cajas", en donde Patricia Tálbot encarnó durante varias ocasiones a la Deidad para dar mensajes a los fieles (Moldstad, 1996).

Sin embargo, el culto a la Virgen lojana no tiene los mismos matices por su arraigo. Es probable que el clero, prioste y organizador de las ceremonias y tradicional aliado del grupo conservador dominante 
de la política de este sector, afiance los valores inmanentes a aquella doctrina política, pero, evidentemente, la imagen pertenece a todos y ha desencadenado un creciente fervor, un ardoroso anhelo por parte del Ecuador y allende este país.

\section{LA FIESTA}

El Cisne está ubicado en las estribaciones del Fierro Urco, de la cordillera occidental a $2.440 \mathrm{~m}$. sobre el nivel del mar, de irregular paisaje.

Se sitúa a 72 kilómetros al noroccidente de la ciudad de Loja; su acceso se realiza desde la parroquia de San Pedro de la Bendita (22 $\mathrm{km}$.). Aunque hay una amplia carretera, los miles de peregrinos prefieren cubrir este tramo a pie, muchas veces descalzos, e incluso un corto tramo lo hacen arrodillados. Siendo el único santuario del extremo sur ecuatoriano, goza de un singular prestigio religioso y es centro de la más alta fe en Dios y en la Virgen. Los habitantes del sector son descendientes de los antiguos paltas y viven de la agricultura aunque las terribles seguías han determinado varios éxodos. El cisneño es amante de la música y en la actualidad hay cinco bandas bien organizadas.

Existe, sin embargo, una fuerte influencia española marcada en la arquitectura y en la lengua.

"En lo referente a la cuestión religiosa, la historia del Santuario y la devoción de Nuestra Señora de El Cisne comienzan el doce de octubre de 1594, cuando, según la tradición, María se aparece a una humilde pastora a quien le pide la erección de un templo para su veneración. Mas los padres de la chica dieron oídos sordos a su versión. La Virgen se manifiesta entre los principales del pueblo a quienes sugiere nuevamente lo pedido a la pastora, los mismos que deciden viajar a Quito y encargar al gran Diego de Robles la escultura de la Virgen, la que se exhibe en la basílica de este pueblo. 
Apenas llegada, se erigió una capillita primitiva, una choza en realidad. Desde el comienzo se manifiestan los prodigios. La imagen policromada mide $64 \mathrm{~cm}$. de estatura, lo que sumados a los 16 de pedestal, dan ochenta $\mathrm{cm}$. de altura. Por su mirada tan bien lograda es Madre de El Cisne. Las coronas y cetros de la Virgen María y del Niño Jesús, adornadas con piedras preciosas y trabajadas en oro puro, pesan dos kilos. Una aureola de oro de $80 \mathrm{~cm}$. de diámetro, lleva en su interior a la Virgen.

Desde los inicios la devoción por la imagen cobró gran importancia por todo el sur de la Real Audiencia de Quito y el norte del Virreinato del Perú. Cuenta la tradición que los habitantes de pueblos aledaños como Chuquiribamba y Zaruma, ansiosos de guardar la estatua se la llevaron para venerarla, pero milagrosamente ella regresó a su santuario, hecho constatado porque las vestiduras estaban embadurnadas de barro.

En El Cisne, hasta la fecha, se han levantado cuatro santuarios.

El "primitivo", que no fue sino una humilde choza con cubierta de paja, dadas las condiciones de la época en la que fue construido, 1596.

El segundo fue la ampliación del primero, pero cambiada la paja de su techo por tejas, 1618.

De 1570 data el tercero, construido con adobes y tejas. Su interior fue enriqueciéndose paulatinamente con hermosas imágenes trabajadas por afamados artistas como Pampite o Legarda y fue embellecido con retablos de estilo Churrigueresco bañados con pan de oro.

El cuarto templo, el actual, comienza a erigirse el 15 de agosto de 1934 concluyéndose el 17 de noviembre de 1978; el estilo es gótico; tiene $65 \mathrm{~m}$. de largo, 40 de ancho y 30 de altura. Es la famosa Basílica de Nuestra Señora de El Cisne. Su financiamiento se debe a la contribución que año tras año ofrecen a la sagrada imagen sus 
peregrinos" (Comunidad de Padres Oblatos, s.f.).

Refiriéndonos a las peregrinaciones, hay que indicar que se trata de una de las imágenes más veneradas por los ecuatorianos quienes la visitan durante todo el año. También acuden muchas personas del norte peruano.

Las procesiones más espectaculares se dan en mayo, agosto y septiembre.

Durante el primero acuden grandes multitudes de Loja, El Oro y Azuay, para lo que se ha establecido un calendario de visitas. De la capital lojana llegan principalmente delegaciones de comités, instituciones culturales, cooperativas, sindicatos, asociaciones, etc. El 30 de mayo se celebra la "Misa de Fiesta" o "Mis Principal". El 15 de agosto se celebra la "Fiesta Principal" o "Fiesta Mayor" a la que concurren devotos de muchas partes, pero principalmente de Azuay, Loja, Cañar, Zamora Chinchipe y Perú. Constituye un día de júbilo para miles y miles de fieles.

El 8 de septiembre es también visitado el santuario, pero con una concurrencia mucho menor que en los otros meses debido a que la fiesta principal ocurre en la ciudad de Loja a donde es transportada la sagrada imagen. Esta fiesta religiosa anual ha cobrado una importancia extraordinaria en las últimas décadas y específicamente desde el 8 de septiembre de 1930, cuando la imagen de Nuestra Señora de El Cisne fue coronada canónicamente y declarada Madre y Reina del Pueblo Lojano, al tiempo que el cabildo y el clero de la Diócesis de Loja la declararon su Patrona.

Los peregrinos la llaman "La Viajerita" por su anual traslado desde su santuario a la capital provincial. Esto data desde que un decreto de 1829 del Libertador Simón Bolívar, dispuso esta visita, para que presida la feria comercial y religiosa del 8 de septiembre.

En tal recorrido le acompañan miles de devotos quienes muy contentos le ofrecen el sacrificio de cubrir 72 kilómetros, "la caminata 
más larga del mundo", bajo un asfixiante sol o agobiados por la lluvia, el viento, la sed, el frío, a pesar de lo cual no desmayan en su propósito, pues lo que más importa es cumplir con la promesa.

La caminata se lleva a cabo desde el 17 de agosto, en que sale de su santuario, para arribar a la población de San Pedro de la Bendita por la tarde, en donde sus pobladores le rinden culto y al siguiente día continúa el periplo hacia el cantón Catamayo, sitio que le hospeda el 18 y19, para continuar finalmente la epopeya hasta la ciudad de Loja cuando raya el alba del 20; hace su triunfal entrada alrededor de las seis de la tarde, en medio del entusiasta clamor de unas cincuenta mil almas.

Alli permanece hasta el primero de noviembre, fecha del retorno a su basílica, sitio visitado durante todo el año por unos cuatrocientos mil fieles.

Hay que anotar que las fechas claves de mayo, agosto y septiembre, concitan el interés más asombroso de la religiosidad popular del austro ecuatoriano, equiparable quizá, en el orden numérico, sólo a la afluencia que acredita el "Pase del Niño Viajero" cuencano. Sin embargo, las diferencias entre estas procesiones son notables, tanto porque en Cuenca hay una sola mantenedora y en Loja es la corporación eclesiástica en general, encabezada por la orden oblata, cuanto porque la participación infantil en Loja no es muy notoria, ni se da el sistema redistributivo que hay en Cuenca. El peregrinaje de la Virgen de El Cisne responde a una tradición enclavada en siglos de historia y milagros y alcanza ribetes de martirio. Así, durante su ascenso desde Catamayo, la gente, en su mayoría adulta, se exaspera tanto que de rodillas y gimiendo, canta, implora y promete. De lado y lado de la ruta hay un sistema de toldos y ventas sobre todo de comidas como empanadas, dulces, "charoles" de cigarrillos, caramelos; no faltan los escapularios y vendedores que deambulan con pequeñas estampas de la Patrona y Reina; hay gritos de la policía, que siempre trata de que la multitud no se aproxime demasiado a la efigie pues todos quieren tocar su manto y muchos lo logran; la caravana es muy apretada allá en donde la carretera es 
angosta; la entrada a Loja es increíblemente triunfal, sobrecogedora; no hay lojano ajeno al gran acontecimiento pues ni siquiera las fiestas de la fundación, el 8 de diciembre, o de la emancipación, 18 de noviembre, son tan increíblemente concurridas.

Porque la "Churona", como cariñosamente ha sido bautizada, es milagrosa; así (Comunidad de Padres Oblatos, s.f.: 12).

"Una aterradora calamidad vio pasar delante de sus ojos la entonces provincia de Ambocas, de la cual era anexo El Cisne, millones de ratones como una manta fatal subían por las colinas y descendían por las llanuras acabado los sembrados. Los pobladores aterrados viendo cerca la miseria y la muerte, acudieron a la Madre Santísima de El Cisne, y juráronla edificar una mejor iglesia si conjuraba el flagelo. La Augustísima Señora oyó su plegaria y en contados días desapareció la plaga. Este milagro fue uno de los que más divulgaron la celebridad misericordiosa de la Taumaturga Imagen de El Cisne". (Aunque el opúsculo no se refiere a una fecha determinada, el relato parece corresponder a la última década del siglo $\mathrm{XVI})$.

Describamos sucintamente lo que en Loja acontece durante los días siete y ocho de septiembre en honor ala venerada imagen:

\section{Víspera, septiembre 7:}

Música de banda desde la mañana. A las $18 \mathrm{~h}$. comienzan a llegar los castillos, hay mucha gente en los alrededores de la iglesia y dentro de ella; vienen de muchos lugares aunque es notoria la presencia de fieles azuayos.

En el parque central hay innumerables "cholas" de Cuenca, muchas de las cuales han venido desde sus lugares de origen.

Hay que decirlo, no hay abundante trago como en otras partes, lo que hace la diferencia con algunas fiestas conocidas. 
Alinean los castillos frente a la iglesia con intervalos de 15 ó 20 m. entre ellos.

La iglesia ha sido visitada durante todo el día por los devotos. Todos se santiguan con agua bendita al entrar. Ella tiene dos naves laterales con santos a un lado, arcos de medio punto. Salen con la mano en el pecho. En la sacristía venden escapularios; a las 18:30 un sacerdote hace rezar el Rosario.

A las 20 h. hay cada vez más gente, un grupo de música típica, de Saraguro, al mismo tiempo que los militares, entona; frente a la iglesia, pequeña orquesta; la gente camina por todas las calles que confluyen en la plaza central; antes de los castillos, igualmente cuetes, destellos. Es importante para los feligreses porque no es tradicional de Loja la pirotecnia. Bullicio de vendedores. Impresionante la cantidad de gente. Globos antes de los castillos; la policía mantiene el orden; exclusivamente personas "del pueblo".

Hay una vaca loca que es paseada en carro, venden canguil.

Cada media hora queman un castillo; el primero a las 20:30; la multitud da vueltas y vueltas.

Ventas ambulantes: Chuzos, cigarrillos, algodón, iqué rico oiga!, manzanas, canguil, suenan cuetes, hay música de altoparlante, hacia el norte, por igual, hombres y mujeres, horchata.

Hay un grupo de música de la Universidad de Piura, otro de danza, de la Universidad de Loja.

Septiembre 8:

Repique de campanas a las 8:30; música sacra; mucha gente dentro de la iglesia. Un carro de la policía para resguardar el orden y proteger a la Virgen. Continúan las ventas ambulantes.La gente entra y sale antes de la procesión. Se escucha cánticos en la iglesia. Se celebra una misa de más de una hora y media antes de la 
procesión. Hay mucha gente que sigue la ceremonia fuera de la iglesia e incluso en el parque, en donde se continúa escuchando cuetes.

La comunión dan varios sacerdotes y no sólo el principal. Turistas que filman. Enorme número de comulgantes. Hay gente que oye misa caminando. Multitud que sale de la misa con flores y sombrero en mano antes de la procesión. Mientras comulgan hay música. La misa es transmitida por radio Nacional del Estado.Verdadero tumulto. Siguen los cánticos. Una hora cuarenta y cinco minutos aún no se termina la misa. Siguen los cánticos.

Salen cantando y toman la calle Valdivieso. El cura indica que ha habido, gracias a ella, cuatrocientos años de amor.

Abandona mucha gente antes la iglesia; asoma Ella precedida de estandartes y mucho incienso, cruces, velas encendidas y muy bien escoltada; la misa termina a las 10h30. Muchos fieles adelante; cuando sale todos la aplauden.

Manto rosado, velo blanco, gran corona de oro. Los globos se elevan; hay muchos apostados a lo largo del parque y es muy solemne el momento; va en medio de la multitud, miles de personas. Se releva la gente para cargarla; le echan flores, todos quieren tocarla. Un atronador aplauso antes de que entre nuevamente en la catedral. Nuevamente grandes ovaciones y cuetes. Detrás de la vaca loca en un carro, el mismo de la víspera; conmovedor y jubiloso. La gente no se retira. Todo el mundo quiere tocarla; hay inválidos en sillas de ruedas con sus familiares. Luego, música popular. Continúa la afluencia hacia la iglesia en medio de las ventas; los sermones continúan.

A las $20 \mathrm{~h}$. hay un concierto de la banda militar, que entona pasillos; se observa poca gente en el parque y los alrededores de la iglesia. 
También están colocados cuatro castillos dispuestos como en la víspera y continúan las ceremonias en la iglesia pues se escucha constantemente "Hosana. Hosana". Todo el día se han pasado misas pero a esta hora se celebra la última, con mucho menos personas. La Reina del Cisne, la Ojona, la Churona, continúa en exposición, y los creyentes compran siempre joyas, escapularios, "souvenirs"; a cien sucres las velas. Se escucha los petardos. Llega un quinto castillo que lo arreglan. Al pasar por la iglesia, todo el mundo hace la señal de la cruz; en el parque se pasean payasos con globitos que hablan.

Un grupo de jovencitos, con botella de trago en mano, se divierte en una banca del parque, en donde la niñez pasea en carros-trenes; hay niños que se asustan de los cuetes.

Muchos vendedores "informales", niños y adultos, hombres y mujeres, que venden las más diversas chucherías.

El día 9 continúa la afluencia de entes a la iglesia y las ventas no se paran.

Desde el 4 la fiesta es en la catedral; desde el 20 de agosto que llega a las seis de la tarde, hay una gran misa celebrada por el obispo y, luego, constantes ceremonias. El 25 sale de recorrido: San Francisco y todas las iglesias; el 1 de noviembre va a La Toma y a El Cisne arriba el 18.

\section{NOTAS}

1. Habríamos querido complementar el subtítulo con algo así como ... Y africanos, pero, a excepción de la provincia de Esmeraldas y muy pocos otros enclaves, la población africana en el Ecuador no está muy extensamente representada en la cultura popular. 


\section{BIBLIOGRAFIA}

BASTIDE, R. Eléments de Sociologie Religieuse. Librairie Armand Collin, París, 1935.

CIEZA DE LEON, P. La Crónica del Perú. Historiadores Primitivos de Indias, Biblioteca de Autores Españoles, t. 26, Madrid, 1947.

COMUNIDAD DE PADRES OBLATOS, Novena en honor a la Virgen del Cisne. Impreso en Offset Atlántida, Cuenca, s.f.

GONZALEZ MUÑOZ, S. El pase del Niño, Imprenta de la Universidad de Cuenca, Cuenca, 1981.

HELLE, J. Les miracles. Ediciones Sun, París, 1949.

MALO GONZALEZ, C. Arte y Cultura Popular, Universidad del Azuay, Centro Interamericano de Artesanías y Artes Populares (CIDAP), Cuenca, 1996.

MOLDSTAD, G.M. Guardiana de la fe (Oposición religiosa y negociación de identidad, los nobles de Cuenca), Ediciones Abya-Yala, Quito, 1996.

SALINAS LOYOLA, J. de. Relación y descripción de la ciudad de Loxa. En Relaciones Histórico-Geográficas de la Audiencia de Quito (Siglos XVIXIX), Pilar Ponce Leiva comp., pp. 122-142, Ediciones Abya-Yala, Quito, 1992 (1571). 